From the Department of Medical Oncology, San Camillo and Forlanini Hospitals, Rome, Italy; Ludwig Oncology Unit, Austin Hospital, Melbourne, Australia; National Oncological Institute, Klenová, Bratislava, Slovakia; Department of Oncology, Military Institute of Medicine, Warsaw, Poland; Department of Urology, Seoul National University College of Medicine, Seoul, Korea; The South West Wales Cancer Institute, Singleton Hospital, Swansea; Cancer Research UK, Department of Medical Oncology, University of Manchester; Christie Hospital National Health Services Foundation Trust, Manchester, United Kingdom; Oncology Research Unit, Oncology Service, Hospital Sao Lucas, Pontifícia Universidade Católica do Rio Grande do Sol, Porto Alegre, Brazil; Division of Medical Oncology and Hematology, Fundación Arturo López Pérez, Santiago, Chile; Chelyabinsk Regional Oncology Center, Chelyabinsk, Russian Federation; Krankenhaus Heitzing, mit Neurologischem Zentrum Rosenhugel, Vienna, Austria; Centro Médico San Roque, Tucumán, Argentina; GlaxoSmithKline, Collegeville, PA; and GlaxoSmithKline, Research Triangle Park, NC

Submitted May 5, 2009; accepted October 27, 2009; published online ahead of print at www.jco.org on January 25, 2010.

Supported by GlaxoSmithKline Pharmaceuticals, Philadelphia, PA. I.D.D. is supported by a Victorian Cancer Agency Clinical Researcher Fellowship and is an honorary National Health and Medical Research Council Practitioner Fellow.

Authors' disclosures of potential conflicts of interest and author contributions are found at the end of this article.

Clinical Trials repository link available on JCO org.

Corresponding author: Cora N. Sternberg, MD, FACP, Department of Medical Oncology, San Camillo Forlanini Hospital, Circonvallazione Gianicolense 87, Rome, Italy 00152; e-mail: cstern@mclink.it.

() 2010 by American Society of Clinical Oncology

0732-183X/10/2806-1061/\$20.00

DOI: 10.1200/JCO.2009.23.976

\title{
Pazopanib in Locally Advanced or Metastatic Renal Cell Carcinoma: Results of a Randomized Phase III Trial
}

Cora N. Sternberg, Ian D. Davis, Jozef Mardiak, Cezary Szczylik, Eunsik Lee, John Wagstaff, Carlos H. Barrios, Pamela Salman, Oleg A. Gladkov, Alexander Kavina, Juan J. Zarbá, Mei Chen, Lauren McCann, Lini Pandite, Debasish F. Roychowdhury, and Robert E. Hawkins

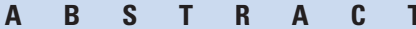

\section{Purpose}

Pazopanib is an oral angiogenesis inhibitor targeting vascular endothelial growth factor receptor, platelet-derived growth factor receptor, and c-Kit. This randomized, double-blind, placebo-controlled phase III study evaluated efficacy and safety of pazopanib monotherapy in treatment-naive and cytokine-pretreated patients with advanced renal cell carcinoma (RCC).

\section{Patients and Methods}

Adult patients with measurable, locally advanced, and/or metastatic RCC were randomly assigned $2: 1$ to receive oral pazopanib or placebo. The primary end point was progression-free survival (PFS). Secondary end points included overall survival, tumor response rate (Response Evaluation Criteria in Solid Tumors), and safety. Radiographic assessments of tumors were independently reviewed

\section{Results}

Of 435 patients enrolled, 233 were treatment naive (54\%) and 202 were cytokine pretreated (46\%). PFS was significantly prolonged with pazopanib compared with placebo in the overall study population (median, PFS 9.2 v 4.2 months; hazard ratio [HR], 0.46; $95 \% \mathrm{Cl}, 0.34$ to 0.62 $P<.0001$ ), the treatment-naive subpopulation (median PFS $11.1 \vee 2.8$ months; $\mathrm{HR}, 0.40 ; 95 \% \mathrm{Cl}$, 0.27 to $0.60 ; P<.0001$ ), and the cytokine-pretreated subpopulation (median PFS, $7.4 \vee 4.2$ months; $\mathrm{HR}, 0.54 ; 95 \% \mathrm{Cl}, 0.35$ to $0.84 ; P<.001)$. The objective response rate was $30 \%$ with pazopanib compared with $3 \%$ with placebo $(P<.001)$. The median duration of response was longer than 1 year. The most common adverse events were diarrhea, hypertension, hair color changes, nausea, anorexia, and vomiting. There was no evidence of clinically important differences in quality of life for pazopanib versus placebo.

\section{Conclusion}

Pazopanib demonstrated significant improvement in PFS and tumor response compared with placebo in treatment-naive and cytokine-pretreated patients with advanced and/or metastatic RCC.

\section{J Clin Oncol 28:1061-1068. (C) 2010 by American Society of Clinical Oncology}

\section{INTRODUCTION}

In the United States, there were 39,226 new cases of renal cell carcinoma (RCC) and 10,662 deaths estimated in 2008. ${ }^{1}$ In the European Union, RCC accounts for approximately $3 \%$ of all cancers in males and $2 \%$ in females. ${ }^{2}$ Approximately $90 \%$ of kidney cancers are RCCs, and $70 \%$ to $80 \%$ of these are of clear-cell histology. ${ }^{3,4}$

Renal cell carcinoma is inherently resistant to cytotoxic therapy, radiation, or hormone therapy. ${ }^{4-6}$ Before the recent advent of angiogenesis inhibitors, cytokine-based therapy including interferon- $\alpha$ (IFN- $\alpha$ ) and/or interleukin-2 (IL-2) were the mainstay of treatment for advanced RCC, despite limited clinical activity and significant toxicity. ${ }^{5,6}$ Advances in the understanding of RCC tumor biology, including the role of vascular endothelial growth factor and mammalian target of rapamycin pathways, led to the successful clinical development of several agents including sorafenib, ${ }^{7}$ sunitinib, ${ }^{8,9}$ bevacizumab (plus IFN- $\alpha$ ), ${ }^{10,11}$ temsirolimus, ${ }^{12}$ and everolimus ${ }^{13}$ for treatment of RCC.

Pazopanib is an oral angiogenesis inhibitor targeting vascular endothelial growth factor receptor, platelet-derived growth factor receptor, and c-Kit. ${ }^{14-16}$ Pazopanib is under clinical development for the treatment of multiple tumor types and has demonstrated monotherapy activity in patients with RCC in phase I/II trials. ${ }^{14-16}$ This randomized, double-blind, placebo-controlled phase III study evaluated the efficacy and safety of 
pazopanib monotherapy in treatment-naive and cytokine-pretreated patients with advanced and/or metastatic RCC.

\section{PATIENTS AND METHODS}

\section{Patients}

This study initially enrolled patients with advanced and/or metastatic RCC who had progressed on one prior cytokine-based systemic therapy. The protocol was subsequently amended to include treatment-naive patients (after enrollment of seven patients) because of emerging evidence of activity of angiogenesis inhibitors and decreased use of cytokines in the first-line setting. Patients without prior systemic therapy could be enrolled provided: they were living in countries where there were barriers to the access of established therapies such as sunitinib, sorafenib, IFN- $\alpha$, or IL- 2 or where cytokines were not recognized as standard treatment for RCC.

Additional eligibility criteria included a diagnosis of clear-cell or predominantly clear-cell histology; measurable disease per Response Evaluation Criteria in Solid Tumors ${ }^{17}$; age $\geq 18$ years; an Eastern Cooperative Oncology Group (ECOG) performance status (PS) $\leq 1$; and adequate renal, hepatic, and hematologic function. Patients were excluded if they had CNS metastasis; leptomeningeal lesions; poorly controlled hypertension (systolic blood pressure of $\geq 140 \mathrm{mmHg}$ or diastolic blood pressure of $\geq 90 \mathrm{mmHg}$, despite antihypertensive therapy); QTc interval $\geq 470$ milliseconds; or a history of the following cardiac and vascular conditions within 6 months of screening: class III/IV congestive heart failure per New York Heart Association classification, cardiac angioplasty or stenting, myocardial infarction, unstable angina, or cerebrovascular accident. The study was approved by local institutional review boards and conducted in accordance with Good Clinical Practice guidelines and the Declaration of Helsinki. All patients provided written informed consent before study-related procedures were performed.

\section{Study Design}

Study VEG105192 (clinicaltrials.gov identifier NCT00334282) was a placebo-controlled, randomized, double-blind, global, multicenter, phase III study. Randomization was stratified on the basis of ECOG PS ( $0 v 1)$, prior nephrectomy (yes $v$ no), and prior systemic treatment for advanced RCC (treatment naive $v$ cytokine pretreated). Patients were centrally randomly assigned in a 2:1 ratio to receive either $800 \mathrm{mg}$ pazopanib once daily or matching placebo. Study medications were administered orally 1 hour before or 2 hours after meals. Dose modification guidelines for adverse events (AEs) were prespecified.

Patients received continuous treatment until disease progression, death, unacceptable toxicity, or withdrawal of consent for any reason. Subsequent anticancer therapy for patients with progressive disease was at the discretion of the patients and their physicians. Patients who progressed were unblinded, and if found to be on placebo, had the option of receiving pazopanib via an open-label study (VEG107769), provided they met predefined eligibility criteria. Seventy (48\%) of 145 placebo-arm patients enrolled in VEG107769. An independent data-monitoring committee was established to monitor safety and review interim overall survival data.

\section{End Points and Assessments}

The primary end point was progression-free survival (PFS), defined as the time interval between the date of random assignment and the date of progression or death. The principal secondary end point was overall survival (OS), defined as the time interval between the date of random assignment and date of death. Other secondary end points included confirmed objective response rate (complete response [CR] plus partial response [PR]), duration of response, and safety. Health-related quality of life (HRQoL) was also assessed.

Disease assessments using computed tomography or magnetic resonance imaging were performed at baseline, every 6 weeks until week 24, and every 8 weeks thereafter until progression. Bone scans were performed at least every 24 weeks in all patients and on confirmation of objective response. Objective responses were confirmed at the next scheduled disease-assessment visit. Patients who discontinued study treatment before disease progression were to continue disease assessments until progression or initiation of an alternate anticancer treatment. All imaging scans were evaluated by an independent imaging-review committee (IRC) blinded to study treatment. Tumor response evaluations by the investigators and the IRC were based on Response Evaluation Criteria in Solid Tumors. ${ }^{17}$ Follow-up for OS was performed every 3 months after disease progression until death or study withdrawal.

Clinical assessments for safety, including physical examinations, vital signs (with blood pressure monitoring), clinical laboratory evaluations, ECG, ECOG PS, and AEs, were evaluated at baseline, day 8, every 3 weeks until week 24 , and every 4 weeks thereafter until study treatment discontinuation. Thyroid function tests were performed every 12 weeks and if thyroid-stimulating hormone levels were abnormal, evaluations of free triiodothyronine/thyroxine

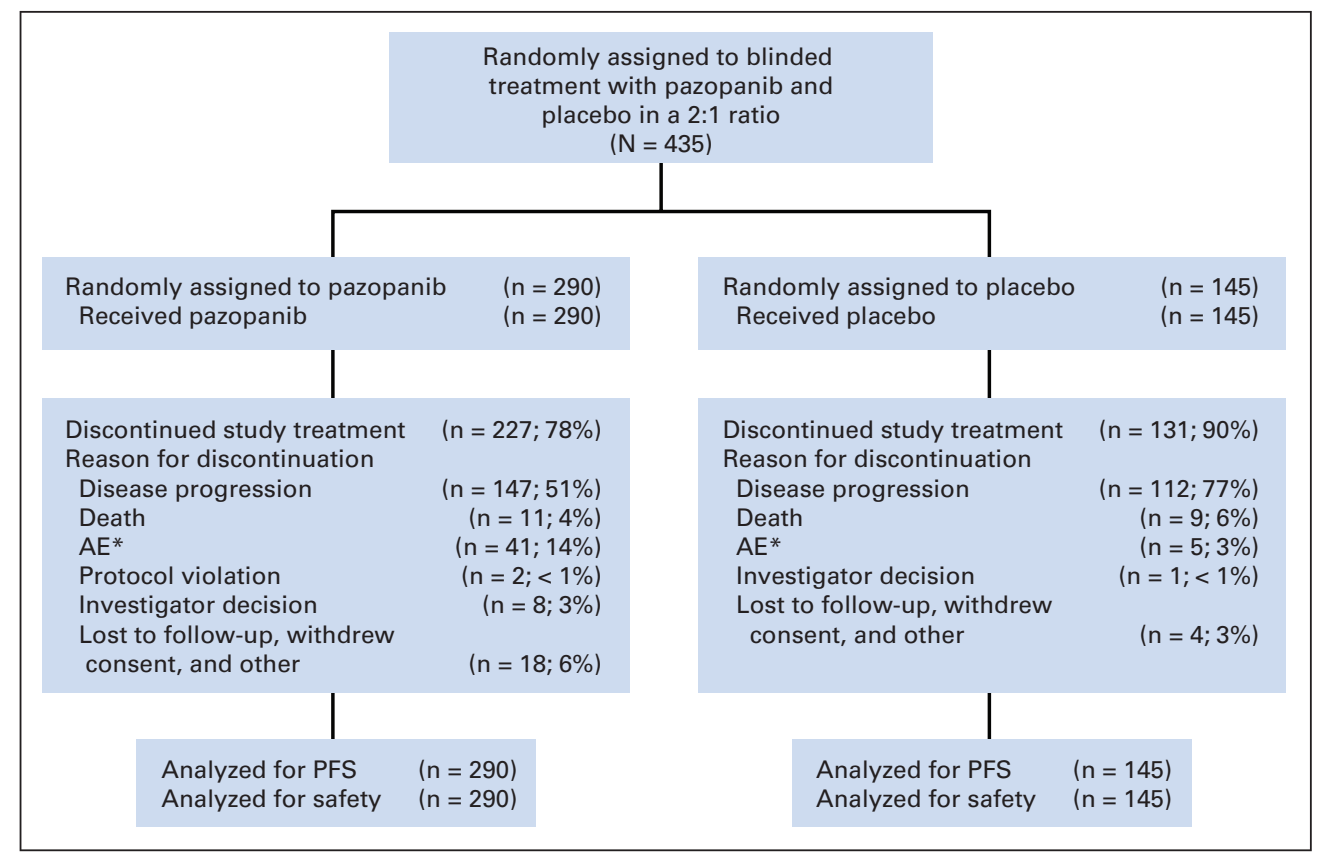

Fig 1. CONSORT diagram. $A E$, adverse event; PFS, progression-free survival. (*) This does not include three patients who, in addition to AEs, had concurrent other reasons at the time they discontinued participation in the study. 
were obtained. Adverse events were graded according to National Cancer Institute Common Toxicity Criteria for Adverse Events version 3.0. ${ }^{18}$

Patient-reported HRQoL was assessed using the European Organisation for Research and Treatment of Cancer Quality of Life Questionnaire (EORTC QLQ-C30 version 3) and the EuroQol (EQ-5D) questionnaires at baseline and at weeks $6,12,18,24$, and 48.

\section{Statistical Methods and Analysis}

Target enrollment and event requirements were defined to provide at least $90 \%$ power to detect an $80 \%$ improvement (hazard ratio [HR], 0.56) in PFS (primary end point) and $90 \%$ power to detect a $50 \%$ improvement (HR, 0.67 ) in OS (secondary end point). After the amendment to include treatmentnaive patients, PFS event requirements were amended to additionally provide approximately $80 \%$ power to detect an $80 \%$ improvement (HR, 0.56 ) or $90 \%$ power to detect a $100 \%$ improvement $(\mathrm{HR}, 0.5)$ in PFS in each subpopulation (ie, treatment naive and cytokine pretreated).

There were no planned (or unplanned) interim analyses for PFS. An interim analysis of OS was to be performed at the time of the final PFS analysis. Thus, the sample size calculation for OS included one planned interim analysis (after $70 \%$ of the required deaths) using flexible O'Brien-Fleming type error spending functions for superiority and futility. All sample size calculations were performed assuming a one-sided $2.5 \% \alpha$ and a 2:1 randomization.

Based on the above requirements, final PFS analysis was planned to be performed after at least 90 PFS events (by IRC) in each subpopulation and at least 160 deaths; final analysis of OS was planned to be performed after 287 deaths. The resulting planned enrollment of the study was a total of 400 patients with 150 to 250 patients in each subpopulation.

Efficacy end points were analyzed in all patients randomized to a treatment arm according to the intention-to-treat principle. Safety analyses were performed on the basis of the actual treatment received in patients who were randomized and received $\geq$ one dose of investigational product.

Kaplan-Meier methods were used to analyze PFS and OS. Comparisons between arms were made using a log-rank test (one sided) stratified by ECOG PS and prior therapy. Hazard ratios were calculated using a stratified Pike estimator utilizing the same factors. The primary analysis of PFS was based on IRC assessments. Progression and censoring dates for the primary analysis were assigned to the visit time point for scheduled visits. Progressions found at unscheduled visits were assigned to the next scheduled visit time point to adjust for any unplanned deviations from the protocol-defined visit schedule, as agreed to with the United States Food and Drug Administration during the study-design process. Nine predefined sensitivity analyses of PFS were performed to confirm the robustness of the primary result using various assumptions, including alternate definitions of progression and censoring dates, data sources (IRC $v$ investigator), and analysis methods. Comparison of PFS between treatment arms was done using the log-rank test in predefined subgroup analyses based on prior treatment, age, sex, Memorial Sloan-Kettering Cancer Center (MSKCC) risk group, ${ }^{19}$ and ECOG PS. Approximate 95\% CIs for response rate (RR) differences were calculated. Duration of response and time to response were summarized descriptively using medians and quartiles.

A mixed-model repeated-measures analysis of change from baseline was performed for QoL measures that were collected by blinded patient selfreports using the EORTC QLQ-C30 and EQ-5D questionnaires. ${ }^{20,21}$ The key end points for these analyses were summary scores from these questionnaires that included the EORTC QLQ-Global Health Status/QoL Score, EQ-5D Index, and EQ-5D visual analog scale (VAS). The minimal important differences (MID) for these questionnaires were previously established as 5 to 10 for EORTC QLQ-C30, ${ }^{22} 0.08$ for EQ-5D Index, and 7 for EQ-5D VAS. ${ }^{23}$

\section{RESULTS}

\section{Patients}

Of 435 patients with advanced and/or metastatic RCC (233 treatment naive; 202 cytokine pretreated) were enrolled between April 2006 and April 2007 from 80 centers in Europe, Asia, South America, North Africa, Australia, and New Zealand; 290 patients were randomly assigned to pazopanib and 145 were randomly assigned to placebo.

At the cutoff date (May 23, 2008), 78\% of patients in the pazopanib arm and $90 \%$ of patients in the placebo arm had discontinued study treatment. Disease progression was the most common reason for death and discontinuation (Fig 1). Demographic and disease characteristics were well balanced between treatment arms (Table 1). All patients had clear cell or predominantly clear-cell histology.

\begin{tabular}{|c|c|c|c|c|}
\hline \multirow[b]{2}{*}{ Parameter } & \multicolumn{2}{|c|}{$\begin{array}{l}\text { Pazopanib } \\
(n=290)\end{array}$} & \multicolumn{2}{|c|}{$\begin{array}{l}\text { Placebo } \\
\text { ( } \mathrm{n}=145)\end{array}$} \\
\hline & No. & $\%$ & No. & $\%$ \\
\hline Median age, years & \multicolumn{2}{|c|}{59} & \multicolumn{2}{|c|}{60} \\
\hline Range & \multicolumn{2}{|c|}{$28-85$} & \multicolumn{2}{|c|}{$25-81$} \\
\hline \multicolumn{5}{|l|}{ Sex } \\
\hline Male & 198 & 68 & 109 & 75 \\
\hline \multicolumn{5}{|l|}{ Race } \\
\hline White & 252 & 87 & 122 & 84 \\
\hline Asian & 36 & 12 & 23 & 16 \\
\hline Black & 1 & $<1$ & 0 & \\
\hline Other & 1 & $<1$ & 0 & \\
\hline \multicolumn{5}{|l|}{ Histology* } \\
\hline Clear cell & 264 & 91 & 129 & 89 \\
\hline Predominantly clear cell & 25 & 9 & 16 & 11 \\
\hline $\begin{array}{l}\text { Median time since initial dia } \\
\text { months }\end{array}$ & \multicolumn{2}{|c|}{15.7} & \multicolumn{2}{|c|}{13.8} \\
\hline Range & \multicolumn{2}{|c|}{$0-184.0$} & \multicolumn{2}{|c|}{ 1.0-152 } \\
\hline \multicolumn{5}{|c|}{ Most common sites of metastasis } \\
\hline Lung & 214 & 74 & 106 & 73 \\
\hline Lymph nodes & 157 & 54 & 86 & 59 \\
\hline Bone & 81 & 28 & 38 & 26 \\
\hline Liver & 75 & 26 & 32 & 22 \\
\hline Kidney & 66 & 23 & 36 & 25 \\
\hline \multicolumn{5}{|l|}{ No. of organs involved $t$} \\
\hline 1 & 53 & 18 & 20 & 14 \\
\hline 2 & 78 & 27 & 50 & 34 \\
\hline$\geq 3$ & 159 & 55 & 75 & 52 \\
\hline \multicolumn{5}{|l|}{ ECOG performance status } \\
\hline 0 & 123 & 42 & 60 & 41 \\
\hline 1 & 167 & 58 & 85 & 59 \\
\hline \multicolumn{5}{|l|}{ MSKCC risk category $\ddagger$} \\
\hline Favorable & 113 & 39 & 57 & 39 \\
\hline Intermediate & 159 & 55 & 77 & 53 \\
\hline Poor & 9 & 3 & 5 & 3 \\
\hline Unknown§ & 9 & 3 & 6 & 4 \\
\hline Prior nephrectomy & 258 & 89 & 127 & 88 \\
\hline \multicolumn{5}{|l|}{ Prior systemic treatment } \\
\hline Treatment naïve & 155 & 53 & 78 & 54 \\
\hline Cytokine pretreated & 135 & 47 & 67 & 46 \\
\hline
\end{tabular}

Abbreviations: ECOG, Eastern Cooperative Oncology Group; MSKCC, Memorial Sloan-Kettering Cancer Center.

*Histology at initial diagnosis was missing for one patient in the pazopanib arm.

†As defined by the investigator.

$\neq$ One hundred eight of the MSKCC risk group assignments required the use of total calcium measurements because of missing baseline albumin levels to calculate corrected calcium.

§Patients with an unknown MSKCC risk category were missing results for one or more of the five risk criteria. 


\section{Efficacy: PFS}

At the final PFS analysis, 148 patients progressed on pazopanib and 98 patients progressed on placebo, based on independent review. In the treatment-naive and cytokine-pretreated subpopulations, 130 and 116 PFS events were recorded, respectively. Pazopanib significantly prolonged PFS compared with placebo in the overall study population (median PFS, $9.2 v 4.2$ months; HR, $0.46 ; 95 \%$ CI, 0.34 to $0.62 ; P<.0001$ ), the treatment-naive subpopulation (median PFS, $11.1 v 2.8$ months; HR, $0.40 ; 95 \% \mathrm{CI}, 0.27$ to $0.60 ; P<.0001$ ), and the cytokine-pretreated subpopulation (median PFS, $7.4 v 4.2$ months; HR, $0.54 ; 95 \%$ CI, 0.35 to $0.84 ; P<.001$; Fig 2 ).

All nine sensitivity analyses of PFS confirmed the primary PFS result, with HR range of 0.42 to 0.49 . In most cases, larger estimates of treatment effect by pazopanib (ie, lower HRs) were observed with the sensitivity analyses compared with the primary analysis, including PFS based on investigators' assessment (HR, $0.44 ; 95 \% \mathrm{CI}, 0.34$ to 0.57 ; $P<.0001)$. The prespecified subgroup analyses showed that PFS was improved for patients treated with pazopanib compared with placebo regardless of MSKCC risk category, sex, age, or ECOG PS (HR range, 0.40 to $0.52 ; P<.001$ by $\log$-rank test for all; Fig 3 ).

\section{Tumor Response}

The RR (by independent review) for pazopanib-treated patients in the overall study population was 30\% (95\% CI, 25.1 to 35.6), with a median duration of response of 58.7 weeks. A similar RR was seen in pazopanib-treated patients in the treatment-naive (32\%) and cytokine-pretreated (29\%) populations (Table 2). The investigatorassessed RR in the overall population (36\%; 95\% CI, 30.0 to 41.0 ; median duration of response of 62.4 weeks) is consistent with RR based on independent review.

\section{Interim OS}

The interim analysis of OS in the overall study population was based on 176 death events, which was $61 \%$ of the required 287 death events for the final OS analysis. The interim OS result did not cross the prespecified O'Brien-Fleming boundaries for either superiority or futility. Final OS results will be reported when data are mature.

\section{Safety}

The median duration of exposure to treatment was approximately double in the pazopanib arm compared with placebo $(7.4 v 3.8$ months). At the time of data cutoff, $32 \%$ of patients on pazopanib and $15 \%$ of patients on placebo had received treatment for more than 12 months.

Most AEs were grade 1/2 (Table 3). Diarrhea (52\%), hypertension (40\%), hair color changes (38\%), nausea (26\%), anorexia (22\%), and vomiting $(21 \%)$ were the most common AEs reported in the pazopanib arm. Proportions of patients experiencing an AE with maximum grade of 3 or 4 were $33 \%$ and $7 \%$, respectively, in the pazopanib arm compared with $14 \%$ and $6 \%$, respectively, in the placebo arm. The most common grade $3 / 4$ AEs in the pazopanib arm were hypertension $(4 \%)$ and diarrhea $(4 \%)$. The AE profile was similar in treatment-naive and cytokine-pretreated patients, although discontinuation rates because of AEs were higher in cytokinepretreated (19\%) compared with treatment-naive (12\%) patients.

Arterial thrombotic events occurred in 3\% of pazopanib-treated patients (myocardial infarction/ischemia [2\%], cerebrovascular accident $[<1 \%]$, and transient ischemic attack $[<1 \%]$ ) compared with

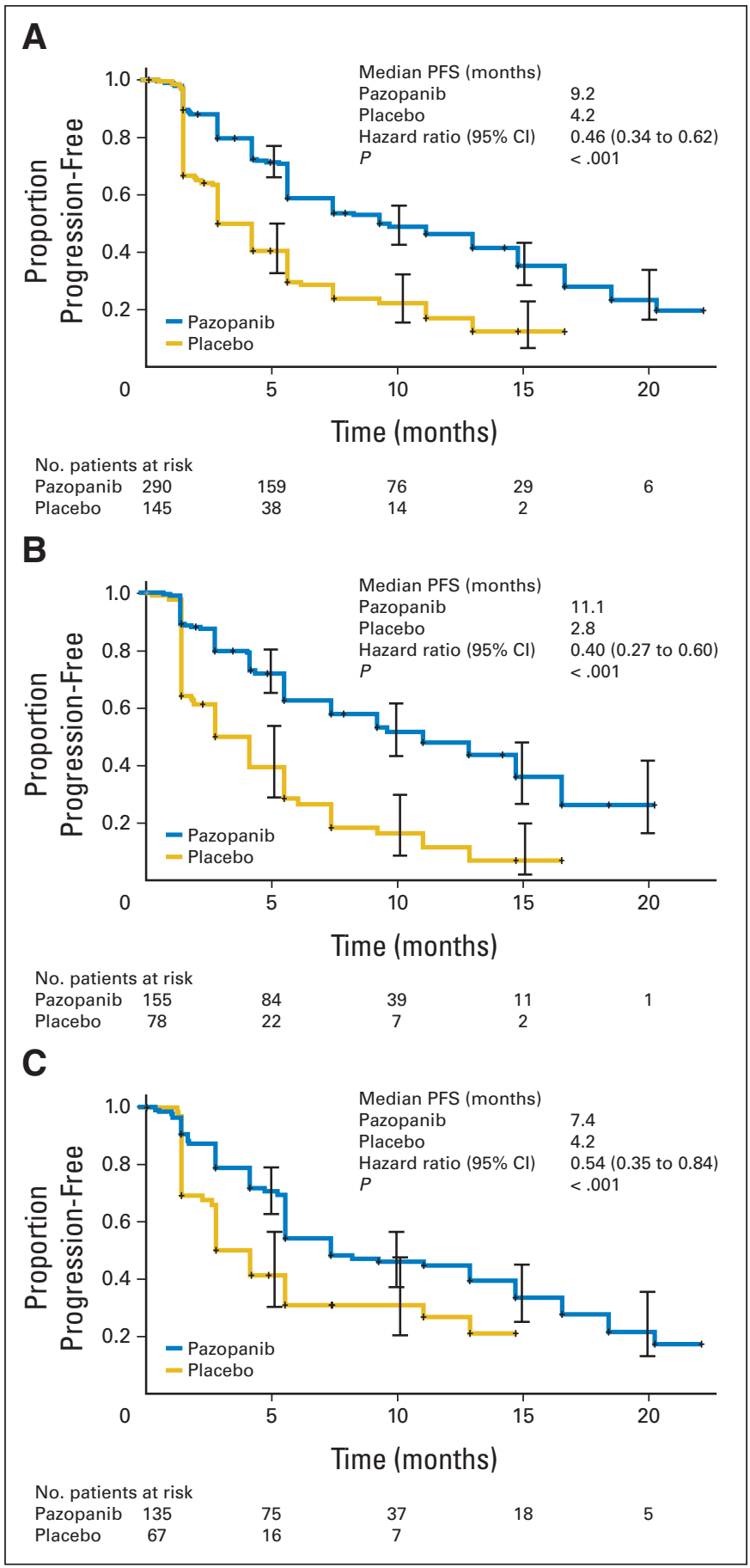

Fig 2. Kaplan-Meier survival curve of progression-free survival (PFS) by independent review in (A) overall study population, (B) treatment-naive population, and $(C)$ cytokine-pretreated population. The difference in median PFS between cytokine-naive and cytokine-pretreated placebo patients is an artifact of the visit-based analysis.

none in the placebo arm. The incidence of hemorrhagic events (all grades) in the pazopanib arm was $13 \%$ compared with $5 \%$ in the placebo arm.

Most laboratory abnormalities were grade $1 / 2$ (Table 3). The most common clinical laboratory abnormalities observed in the pazopanib arm were ALT elevation and AST elevation. Elevations in 


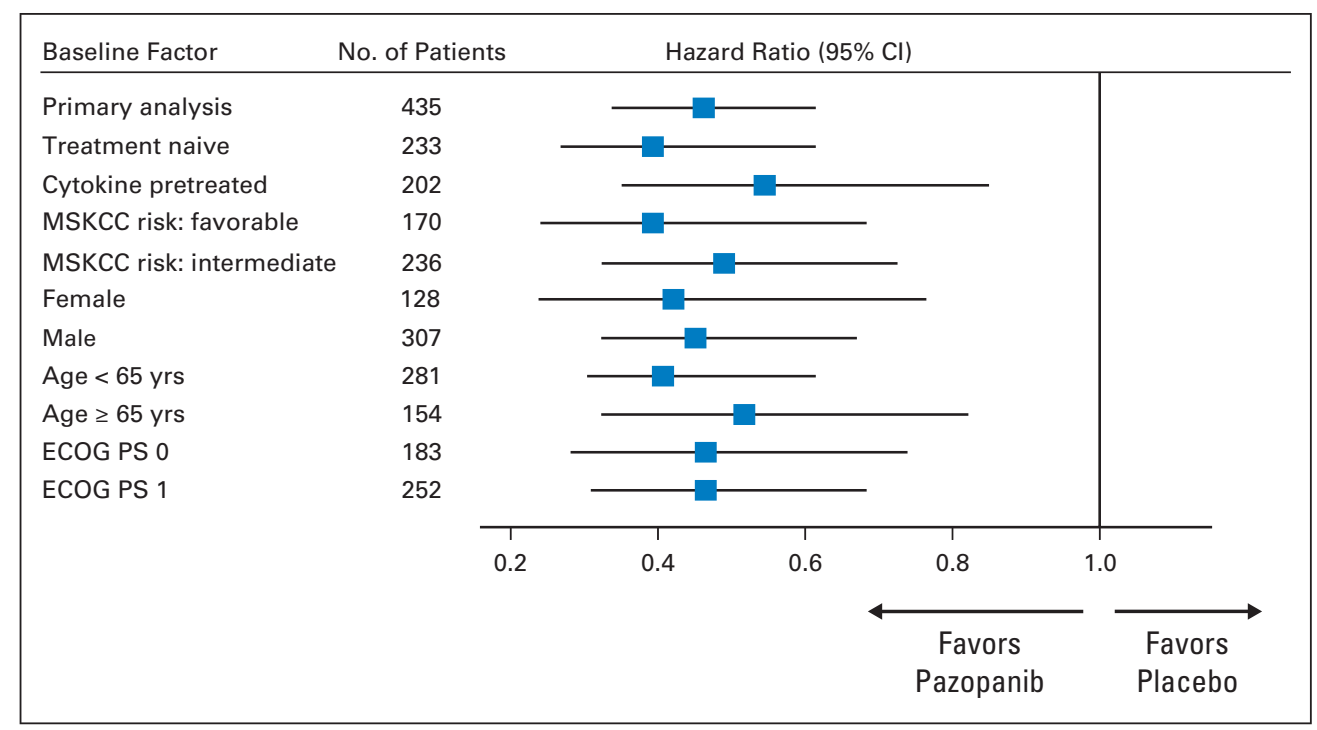

Fig 3. Predefined subgroup analysis of progression-free survival per independent review. MSKCC, Memorial Sloan-Kettering Cancer Center; ECOG PS, Eastern Cooperative Oncology Group performance status.

ALT $\geq 3 \times$ the upper limit of normal occurred in 52 pazopanibtreated patients (18\%): ALT elevation recovered to $\leq$ grade 1 after dose modification, interruption, or discontinuation in 45 patients (87\%); seven patients (13\%) did not have adequate follow-up data to assess recovery.

Death resulting from AEs was reported in $4 \%$ of patients in the pazopanib arm and $3 \%$ of patients in the placebo arm. Four patients (1\%) in the pazopanib arm had fatal AEs that were assessed by the investigator as attributable to study treatment: ischemic stroke, abnor-

Table 2. Summary of Tumor Response by Independent Review

\begin{tabular}{|c|c|c|c|c|}
\hline \multirow[b]{2}{*}{ Parameter } & \multicolumn{2}{|c|}{$\begin{array}{l}\text { Pazopanib } \\
(n=290)\end{array}$} & \multicolumn{2}{|c|}{$\begin{array}{c}\text { Placebo } \\
(\mathrm{n}=145)\end{array}$} \\
\hline & No. & $\%$ & No. & $\%$ \\
\hline \multicolumn{5}{|l|}{ Overall study population } \\
\hline \multicolumn{5}{|l|}{ Best response } \\
\hline Complete response & 1 & $<1$ & 0 & \\
\hline Partial response & 87 & 30 & 5 & 3 \\
\hline Stable disease & 110 & 38 & 59 & 41 \\
\hline Progressive disease & 51 & 18 & 58 & 40 \\
\hline Unknown* & 41 & 14 & 23 & 16 \\
\hline Response rate (CR + PR) & $88+$ & 30 & 5 & 3 \\
\hline $95 \% \mathrm{Cl}$ & \multicolumn{2}{|c|}{25.1 to 35.6} & \multicolumn{2}{|c|}{0.5 to 6.4} \\
\hline Median duration of response, weeks & \multicolumn{2}{|c|}{58.7} & \multicolumn{2}{|c|}{ - } \\
\hline $95 \% \mathrm{Cl}$ & \multicolumn{2}{|c|}{52.1 to 68.1} & \multicolumn{2}{|c|}{ - } \\
\hline Median time to response, weeks & \multicolumn{2}{|c|}{11.9} & \multicolumn{2}{|c|}{-} \\
\hline $95 \% \mathrm{Cl}$ & \multicolumn{2}{|c|}{9.4 to 12.3} & \multicolumn{2}{|c|}{-} \\
\hline Treatment-naive subgroup & 155 & & 78 & \\
\hline Response rate $(\mathrm{CR}+\mathrm{PR})$ & 49 & 32 & 3 & 4 \\
\hline $95 \% \mathrm{Cl}$ & \multicolumn{2}{|c|}{24.3 to 38.9} & \multicolumn{2}{|c|}{0.0 to 8.1} \\
\hline Cytokine-pretreated subgroup & \multicolumn{2}{|c|}{135} & \multicolumn{2}{|c|}{67} \\
\hline Response rate (CR + PR) & 39 & 29 & 2 & 3 \\
\hline $95 \% \mathrm{Cl}$ & \multicolumn{2}{|c|}{21.2 to 36.5} & \multicolumn{2}{|c|}{0.0 to 7.1} \\
\hline
\end{tabular}

Abbreviations: CR, complete response; $\mathrm{PR}$, partial response.

*A patient was classified as unknown if he or she never had progressive disease and did not have stable disease for at least 12 weeks (the minimum requirement to be classified as stable disease). This includes patients with no follow-up and some patients censored by independent review.

$\dagger P<.001$, based on Fisher's exact test comparison of treatment arms. mal hepatic function and rectal hemorrhage, peritonitis/bowel perforation, and abnormal hepatic function (one patient each). The patient who died of peritonitis/bowel perforation had RCC metastasis present at the site of perforation. The later patient who died of abnormal hepatic function was found on autopsy to have extensive infiltration of the liver with metastatic disease.

\section{HRQoL}

Completion rates for QoL questionnaires were high across most of the assessment timepoints for each instrument (>90\%). The longitudinal means for the three QoL end points showed a trend for maintenance of QoL across time between treatment and placebo groups, with differences that were not clinically important according to established MID for the questionnaires. The mixed-model repeated-measures analyses showed no statistical differences between pazopanib and placebo at any of the assessment time points for the three key QoL end points (Table 4). There was a difference in the rate of withdrawal of patients from the placebo arm because of disease progression, which became apparent after week 6 and was especially evident at later assessment timepoints.

\section{DISCUSSION}

In this phase III trial, pazopanib demonstrated a significant improvement in PFS and RR compared with placebo in patients with advanced and/or metastatic RCC in the overall population and in the treatmentnaive and cytokine-pretreated subpopulations. The efficacy of pazopanib observed in this study confirms results observed in a previous phase II trial in patients with advanced RCC (VEG102616; median PFS, 11.9 months; RR, 35\%; median duration of response, 68 weeks). ${ }^{16}$ The effects of PFS and RR in the treatment-naive subpopulation observed in this phase III trial are comparable to published data for sunitinib and bevacizumab (with IFN- $\alpha$ ). ${ }^{8,10,11}$

When this study was initiated in April 2006, limited access to the multikinase inhibitors sunitinib and sorafenib precluded the use of either as a comparator. Therefore, placebo with best supportive care was considered an appropriate comparator for cytokine-pretreated 
Table 3. Common Treatment-Emergent Adverse Events* and Selected Clinical Laboratory Abnormalitiest in Patients With At Least One Adverse Event

\begin{tabular}{|c|c|c|c|c|c|c|c|c|c|c|c|c|}
\hline \multirow[b]{4}{*}{ Parameter } & \multicolumn{12}{|c|}{ Grade } \\
\hline & \multicolumn{6}{|c|}{ Pazopanib (n = 290) } & \multicolumn{6}{|c|}{ Placebo ( $n=145)$} \\
\hline & \multicolumn{2}{|c|}{ Any* } & \multicolumn{2}{|c|}{3} & \multicolumn{2}{|c|}{4} & \multicolumn{2}{|c|}{ Any * } & \multicolumn{2}{|c|}{3} & \multicolumn{2}{|c|}{4} \\
\hline & No. & $\%$ & No. & $\%$ & No. & $\%$ & No. & $\%$ & No. & $\%$ & No. & $\%$ \\
\hline \multicolumn{13}{|l|}{ Adverse event } \\
\hline Diarrhea & 150 & 52 & 9 & 3 & 2 & $<1$ & 13 & 9 & 1 & $<1$ & 0 & \\
\hline Hypertension & 115 & 40 & 13 & 4 & 0 & & 15 & 10 & 1 & $<1$ & 0 & \\
\hline Hair color changes & 109 & 38 & 1 & $<1$ & 0 & & 4 & 3 & 0 & & 0 & \\
\hline Nausea & 74 & 26 & 2 & $<1$ & 0 & & 13 & 9 & 0 & & 0 & \\
\hline Anorexia & 65 & 22 & 6 & 2 & 0 & & 14 & 10 & 1 & $<1$ & 0 & \\
\hline Vomiting & 61 & 21 & 6 & 2 & 1 & $<1$ & 11 & 8 & 3 & 2 & 0 & \\
\hline Fatigue & 55 & 19 & 7 & 2 & 0 & & 11 & 8 & 2 & 1 & 2 & 1 \\
\hline Asthenia & 41 & 14 & 8 & 3 & 0 & & 12 & 8 & 0 & & 0 & \\
\hline Abdominal pain & 32 & 11 & 6 & 2 & 0 & & 2 & 1 & 0 & & 0 & \\
\hline Headache & 30 & 10 & 0 & & 0 & & 7 & 5 & 0 & & 0 & \\
\hline \multicolumn{13}{|l|}{ Clinical chemistry } \\
\hline ALT increase & 152 & 53 & 30 & 10 & 5 & 2 & 32 & 22 & 2 & 1 & 0 & \\
\hline AST increase & 152 & 53 & 21 & 7 & 2 & $<1$ & 27 & 19 & 1 & $<1$ & 0 & \\
\hline Hyperglycemia & 115 & 41 & 2 & $<1$ & 0 & & 47 & 33 & 2 & 1 & 0 & \\
\hline Total bilirubin increase & 102 & 36 & 7 & 3 & 2 & $<1$ & 15 & 10 & 2 & 1 & 1 & $<1$ \\
\hline Hypophosphatemia & 95 & 34 & 11 & 4 & 0 & & 16 & 11 & 0 & & 0 & \\
\hline Hypocalcemia & 91 & 33 & 4 & 1 & 4 & 1 & 35 & 26 & 2 & 1 & 1 & $<1$ \\
\hline Hyponatremia & 86 & 31 & 11 & 4 & 4 & 1 & 35 & 24 & 6 & 4 & 0 & \\
\hline Hypomagnesemia & 31 & 11 & 9 & 3 & 0 & & 13 & 9 & 3 & 2 & 0 & \\
\hline Hypoglycemia & 47 & 17 & 0 & & 1 & $<1$ & 4 & 3 & 0 & & 0 & \\
\hline \multicolumn{13}{|l|}{ Hematologic } \\
\hline Leukopenia & 103 & 37 & 0 & & 0 & & 9 & 6 & 0 & & 0 & \\
\hline Neutropenia & 94 & 34 & 3 & 1 & 1 & $<1$ & 9 & 6 & 0 & & 0 & \\
\hline Thrombocytopenia & 89 & 32 & 2 & $<1$ & 1 & $<1$ & 7 & 5 & 0 & & 1 & $<1$ \\
\hline Lymphocytopenia & 86 & 31 & 11 & 4 & 1 & $<1$ & 34 & 24 & 2 & 1 & 0 & \\
\hline
\end{tabular}

patients. In addition, using a placebo control in a randomized doubleblind design enabled better characterization of the safety and efficacy profile of pazopanib. When the protocol was amended to allow enrollment of treatment-naive patients, placebo with best supportive care was retained as the control arm. (Criteria for enrolling treatmentnaive patients are described in detail in the Patients and Methods section.) Moreover, cytokines as a standard of care were being challenged in some participating countries, based on their unfavorable risk-benefit profile $e^{24,25}$ and emerging data for multikinase inhibitors. Exposure of patients to placebo in the study was minimized by $2: 1$ random assignment, and pazopanib was provided as a treatment option for patients who progressed on placebo.

Pazopanib demonstrated acceptable safety and tolerability. Diarrhea, hypertension, hair color changes, nausea, anorexia, and vomiting were the most commonly reported AEs (incidence of $\geq 20 \%$ ). Most AEs related to pazopanib treatment were grade $1 / 2$ and were clinically manageable. The most common grade $3 / 4$ AEs were hypertension and diarrhea. The most common grade $3 / 4$ chemistry abnormalities were ALT elevation and AST elevation. Most cases of drug-induced liver enzyme elevations were asymptomatic and occurred within the first 4 months of treatment. Certain AEs known to occur with this class of agents, including proteinuria, thrombocytopenia, hypothyroidism, hand-foot syndrome, and mucositis/stomatitis, occurred with an incidence of fewer than $10 \%$ each, with grade $3 / 4$ events reported in less than $1 \%$ of patients. It is notable in the current analysis that patients who were treated with pazopanib did not have a clinically important difference (relative to the MID) in QoL compared with placebo in blinded patient self-reports, despite toxicities that may be expected with an active agent. These results are consistent with the observed tolerability profile for pazopanib, which is particularly important because patients with RCC are often asymptomatic when therapy is initiated and may remain on therapy for prolonged periods of time. Although some AEs observed with pazopanib are related to target inhibition, others may result from off-target activity. Potential differences in the safety profiles of multikinase angiogenesis inhibitors may be explained by differences in the potency and selectivity of kinases inhibited. ${ }^{26}$ Pazopanib, although an inhibitor of c-Kit, is not a potent inhibitor of fms-related tyrosine kinase $3,{ }^{26}$ which may explain the low rate $(\leq 1 \%)$ of grade $3 / 4$ cytopenias observed with pazopanib.

In conclusion, once-daily oral pazopanib significantly improved PFS and RR in treatment-naive and cytokine-pretreated patients with advanced and/or metastatic RCC. Furthermore, pazopanib was well tolerated in this population. These findings support the continued evaluation of the efficacy, safety, and effect on QoL of pazopanib in this patient population. A phase III trial comparing pazopanib monotherapy with sunitinib in treatment-naive patients 


\begin{tabular}{|c|c|c|c|c|c|}
\hline \multicolumn{6}{|c|}{$\begin{array}{l}\text { Table 4. Mixed-Model Repeated-Measures Analyses for OoL Change } \\
\text { From Baseline }\end{array}$} \\
\hline \multirow[b]{2}{*}{ Model } & \multicolumn{2}{|c|}{ No. of Patients } & \multirow[b]{2}{*}{ Differencet } & \multirow[b]{2}{*}{$95 \% \mathrm{Cl}$} & \multirow[b]{2}{*}{$P$} \\
\hline & Pazopanib & Placebo* & & & \\
\hline \multicolumn{6}{|c|}{$\begin{array}{l}\text { EORTC QLQ-C30 Global } \\
\text { Health Status/QoL } \\
\text { by week }\end{array}$} \\
\hline 6 & 243 & 110 & -1.90 & -5.84 to 2.04 & .34 \\
\hline 12 & 219 & 81 & -2.82 & -7.17 to 1.53 & .20 \\
\hline 18 & 191 & 61 & -2.05 & -6.95 to 2.86 & .41 \\
\hline 24 & 164 & 49 & 0.39 & -4.47 to 5.25 & .88 \\
\hline 48 & 96 & 24 & -0.67 & -6.48 to 5.14 & .82 \\
\hline \multicolumn{6}{|c|}{$E Q-5 D$ index by week } \\
\hline 6 & 253 & 125 & 0.01 & -0.04 to 0.05 & .84 \\
\hline 12 & 219 & 86 & -0.04 & -0.09 to 0.01 & .08 \\
\hline 18 & 196 & 62 & -0.02 & -0.08 to 0.04 & .50 \\
\hline 24 & 166 & 51 & -0.03 & -0.09 to 0.04 & .44 \\
\hline 48 & 98 & 24 & 0.03 & -0.03 to 0.10 & .33 \\
\hline \multicolumn{6}{|c|}{ EQ-5D VAS by week } \\
\hline 6 & 239 & 111 & 1.85 & -2.41 to 6.12 & .39 \\
\hline 12 & 212 & 80 & 0.06 & -4.79 to 4.91 & .98 \\
\hline 18 & 189 & 60 & -0.08 & -5.04 to 4.89 & .98 \\
\hline 24 & 161 & 49 & -0.15 & -4.83 to 4.53 & .95 \\
\hline 48 & 95 & 23 & -1.97 & -9.02 to 5.09 & .58 \\
\hline
\end{tabular}

Abbreviations: QoL, quality of life; EORTC OLQ-C30, European Organisation for Research and Treatment of Cancer Quality of Life Questionnaire; EQ-5D, EuroQuol questionnaire; VAS, visual analogue scale.

*More patients in the placebo arm discontinued study treatment because of disease progression compared with patients in the pazopanib arm.

tThe minimal important differences for the questionnaires have been previously established as 5 to 10 for the EORTC-QLQ-C30, 0.08 for the EQ-5D Index, and 7 for the EQ-5D VAS. Values greater than 0 indicate a trend in favor of pazopanib, and values less than 0 indicate a trend in favor of placebo.

with advanced and/or metastatic RCC is ongoing (clinicaltrials.gov identifier NCT00720941).

\section{AUTHORS' DISCLOSURES OF POTENTIAL CONFLICTS} OF INTEREST

Although all authors completed the disclosure declaration, the following author(s) indicated a financial or other interest that is relevant to the subject matter under consideration in this article. Certain relationships marked with a " $U$ " are those for which no compensation was received; those relationships marked with a "C" were compensated. For a detailed description of the disclosure categories, or for more information about ASCO's conflict of interest policy, please refer to the Author Disclosure Declaration and the Disclosures of Potential Conflicts of Interest section in Information for Contributors.

Employment or Leadership Position: Mei Chen, GlaxoSmithKline (C); Lauren McCann, GlaxoSmithKline (C); Lini Pandite, GlaxoSmithKline (C) Consultant or Advisory Role: Ian D. Davis, GlaxoSmithKline (C), Pfizer (C), Wyeth (C), Novartis (C), Bayer Pharmaceuticals (C); Cezary Szczylik, Pfizer (C), Bayer Pharmaceuticals (C); John Wagstaff, GlaxoSmithKline (C); Carlos H. Barrios, GlaxoSmithKline (C); Pamela Salman, Merck (C) Stock Ownership: Mei Chen, GlaxoSmithKline; Lauren McCann,

GlaxoSmithKline; Lini Pandite, GlaxoSmithKline; Debasish F.

Roychowdhury, GlaxoSmithKline; Robert E. Hawkins, GlaxoSmithKline Honoraria: Cora N. Sternberg, GlaxoSmithKline; Cezary Szczylik, Bayer Pharmaceuticals, Roche, Pfizer; Carlos H. Barrios, GlaxoSmithKline; Robert E. Hawkins, GlaxoSmithKline Research Funding: Cora N. Sternberg, GlaxoSmithKline; Ian D. Davis, GlaxoSmithKline; Cezary Szczylik, Bayer Pharmaceuticals; Carlos H. Barrios, GlaxoSmithKline Expert Testimony: None Other Remuneration: None

\section{AUTHOR CONTRIBUTIONS}

Conception and design: Cora N. Sternberg, Mei Chen, Lini Pandite,

Debasish F. Roychowdhury

Financial support: Debasish F. Roychowdhury

Administrative support: Debasish F. Roychowdhury

Provision of study materials or patients: Cora N. Sternberg, Ian D. Davis, Jozef Mardiak, Cezary Szczylik, Eunsik Lee, John Wagstaff, Carlos H. Barrios, Pamela Salman, Oleg A. Gladkov, Alexander Kavina, Lini Pandite, Robert E. Hawkins

Collection and assembly of data: Cora N. Sternberg, Ian D. Davis, Jozef Mardiak, Eunsik Lee, John Wagstaff, Juan J. Zarbá, Mei Chen, Lauren McCann, Lini Pandite, Debasish F. Roychowdhury, Robert E. Hawkins Data analysis and interpretation: Cora N. Sternberg, Ian D. Davis, Cezary Szczylik, Mei Chen, Lauren McCann, Lini Pandite, Debasish F. Roychowdhury, Robert E. Hawkins

Manuscript writing: Cora N. Sternberg, Ian D. Davis, Mei Chen, Lauren McCann, Lini Pandite, Debasish F. Roychowdhury, Robert E. Hawkins Final approval of manuscript: Cora N. Sternberg, Ian D. Davis, Jozef Mardiak, Cezary Szczylik, Eunsik Lee, John Wagstaff, Carlos H. Barrios, Pamela Salman, Oleg A. Gladkov, Alexander Kavina, Juan J. Zarbá, Mei Chen, Lauren McCann, Lini Pandite, Debasish F. Roychowdhury, Robert E. Hawkins

\section{REFERENGES}

1. U.S. Department of Health and Human Services - National Cancer Institute (NCI): Cancer Incidence - Surveillance, Epidemiology, and End Results (SEER) Registries Limited-Use National Cancer Institute, Cancer Statistics Branch, released April 2009, based on the November 2008 submission. www.census.gov/population/www/projections/ usinterimproj/usproj2000-2050.xls

2. Curado MP, Edwards B, Shin HR, et al (eds): Cancer Incidence in Five Continents (vol 9). Lyon, France, International Agency for Research on Cancer (WHO), 2008

3. Diaz JI, Mora LB, Hakam A: The Mainz Classification of renal cell tumors. Cancer Control 6:571579, 1999

4. Nelson EC, Evans CP, Lara PN Jr: Renal cell carcinoma: Current status and emerging therapies. Cancer Treat Rev 33:299-313, 2007
5. Coppin C, Le L, Porzsolt F, et al: Targeted therapy for advanced renal cell carcinoma. Cochrane Database Syst Rev CD006017, 2008

6. van Spronsen DJ, de Weijer KJ, Mulders PF, et al: Novel treatment strategies in clear-cell metastatic renal cell carcinoma. Anticancer Drugs 16:709717, 2005

7. Escudier B, Eisen T, Stadler WM, et al: Sorafenib in advanced clear-cell renal-cell carcinoma. N Engl J Med 356:125-134, 2007

8. Motzer RJ, Hutson TE, Tomczak $P$, et al: Sunitinib versus interferon alfa in metastatic renalcell carcinoma. N Engl J Med 356:115-124, 2007

9. Motzer RJ, Michaelson MD, Rosenberg J, et al: Sunitinib efficacy against advanced renal cell carcinoma. J Urol 178:1883-1887, 2007

10. Escudier B, Pluzanska A, Koralewski $P$, et al: Bevacizumab plus interferon alfa-2a for treatment of metastatic renal cell carcinoma: A randomised, double-blind phase III trial. Lancet 370:2103-2111, 2007
11. Rini $\mathrm{BI}$, Halabi $\mathrm{S}$, Rosenberg JE, et al: Bevacizumab plus interferon alfa compared with interferon alfa monotherapy in patients with metastatic renal cell carcinoma: CALGB 90206. J Clin Oncol 26:54225428, 2008

12. Hudes G, Carducci M, Tomczak $P$, et al: Temsirolimus, interferon alfa, or both for advanced renalcell carcinoma. N Engl J Med 356:2271-2281, 2007

13. Motzer RJ, Escudier B, Oudard S, et al: Efficacy of everolimus in advanced renal cell carcinoma: A double-blind, randomised, placebo-controlled phase III trial. Lancet 372:449-456, 2008

14. Hurwitz H, Dowlati A, Savage S, et al: Safety, tolerability and pharmacokinetics of oral administration of GW786034 in pts with solid tumors. J Clin Oncol 23:195s, 2005 (suppl; abstr 3012)

15. Hutson T, Davis I, Machiels J, et al: Predictive and prognostic factors in phase II renal cell carcinoma trial with pazopanib (GW786034), a multi-kinase angiogenesis inhibitor. Ann Oncol 19:viii187, 2008 (suppl 8; abstr 5780) 
16. Hutson TE, Davis ID, Machiels $\mathrm{JH}$, et al: Biomarker analysis and final efficacy and safety results of a phase II renal cell carcinoma trial with pazopanib (GW786034), a multi-kinase angiogenesis inhibitor. J Clin Oncol 26:261s, 2008 (abstr 5046)

17. Therasse $P$, Arbuck SG, Eisenhauer EA, et al: New guidelines to evaluate the response to treatment in solid tumors. J Natl Cancer Inst 92:205-216, 2000

18. National Cancer Institute Cancer Therapy Evaluation Program: Common Terminology Criteria for Adverse Events v3.0 (CTCAE). http://ctep.cancer.gov/ protocolDevelopment/electronic_applications/docs/ ctcaev3.pdf
19. Motzer RJ, Mazumdar M, Bacik J, et al: Survival and prognostic stratification of 670 patients with advanced renal cell carcinoma. J Clin Onco 17:2530-2540, 1999

20. Aaronson NK, Ahmedzai S, Bergman B, et al: The European Organisation for Research and Treatment of Cancer QLQ-C30: A quality-of-life instrument for use in international clinical trials in oncology. J Natl Cancer Inst 85:365-376, 1993

21. Rabin $R$, de Charro F: EQ-5D: A measure of health status from the EuroQol Group. Ann Med 33:337-343, 2001

22. Osoba D, Rodrigues G, Myles J, et al: Interpreting the significance of changes in health-related quality-of-life scores. J Clin Oncol 16:139-144, 1998
23. Pickard AS, Neary MP, Cella D: Estimation of minimally important differences in EQ-5D utility and VAS scores in cancer. Health Qual Life Outcomes 5:70, 2007

24. Coppin C: Immunotherapy for renal cell cancer in the era of targeted therapy. Expert Rev Anticancer Ther 8:907-919, 2008

25. Negrier S, Perol D, Ravaud A, et al: Medroxy progesterone, interferon alfa-2a, interleukin 2, o combination of both cytokines in patients with metastatic renal carcinoma of intermediate prognosis: Results of a randomized controlled trial. Cancer 110:2468-2477, 2007

26. Karaman MW, Herrgard S, Treiber DK, et al: A quantitative analysis of kinase inhibitor selectivity. Nat Biotechnol 26:127-132, 2008

\section{Sign up for Alerts About Your Topic of Interest}

Learn about new research in your field as it becomes available. Subscribe to a JCO e-mail alert to be notified immediately when new articles within your area of interest are posted.

Receive notification when:

JCO releases a new issue's Table of Contents.

$>$ A new issue of $J C O$ is posted online.

$>$ New articles are published online ahead of print publication.

$>$ New content in your subspecialty is published.

$>$ An article is published online from an author of interest.

Go to jco.org/alerts to sign up. 